\section{Extensive Desiccation and Aging Stress Tolerance Characterize Gaillardia pulchella (Asteraceae) Seeds}

\author{
Yai Ulrich Adegbola \\ Department of Food and Resource Economics, University of Florida, \\ Gainesville, FL 32603
}

\author{
Héctor E. Pérez ${ }^{1}$ \\ Department of Environmental Horticulture, Plant Restoration and \\ Conservation Horticulture Research Consortium, 2047 IFAS Research \\ Drive, Gainesville, FL 32611
}

Additional index words. Cox regression, desiccation tolerance, germination, Kaplan-Meier, saturated salt accelerated aging, seed storage, seed vigor, survival analysis, water sorption isotherms

\begin{abstract}
We investigated the response of Gaillardia pulchella seeds to desiccation and aging stress to gain some perspective on the germplasm storage potential and seed vigor of this species. Seed-water relations of mature, freshly harvested G. pulchella seeds were characteristic of desiccation-tolerant species. For example, initial seed water potential ( $-53 \mathrm{MPa}$ ) was well below the lethal water potential limit ( $-15 \mathrm{MPa})$ for desiccationsensitive seeds. Desiccation tolerance was confirmed by high $(>70 \%)$, rapid $\left(t_{50}\right.$ range $4-7$ days), and uniform germination following equilibration drying. Likewise, post-saturated salt accelerated aging (SSAA) germination tests indicated a high degree of vigor of fresh seeds. The substantial level of desiccation and aging-related stress tolerance in G. pulchella seeds suggests that these organs potentially display orthodox storage physiology and an ability to endure variable seed bed conditions.
\end{abstract}

Desiccation tolerance is a seed trait of significant horticultural importance. For example, the ability to tolerate considerable levels of postharvest desiccation is one of the key factors for maintaining seed viability and extending shelf life during storage (Berjak and Pammenter, 2008; Ellis and Roberts, 1981; Roberts, 1973; Walters, 1998; Walters et al., 2010). Desiccation tolerance manifests during the seed developmental program and has been associated with patterns of maximal dry matter accumulation (i.e., physiological maturity), sharp declines in water content and water potential resulting from vascular separation between the seed and mother plant during the maturation drying phase, and the ability of subcellular components to recover upon rehydration from the stresses and strains imposed by drying (Kermode and Finch-Savage, 2002; Pérez et al., 2012; Walters et al., 2010).

Postharvest drying in equilibrium with low relative humidity (e.g., $20 \%$ RH)

Received for publication 13 Nov. 2015. Accepted for publication 3 Jan. 2016.

Yai Ulrich Adegbola was supported in part through a UF/IFAS Research Summer Internship.

We thank Ryan Brown for a generous donation of seeds used in this work and Fé Almira for logistic support. We also thank Tia Tyler, Nicholas Genna, Matt Kramer, Brent Pemberton, and anonymous reviewers for providing constructive comments. ${ }^{1}$ Corresponding author. E-mail: heperez@ufl.edu.

tion of the United Nations, 2014). But, seed managers are not always able to provide or maintain ideal storage conditions due to financial, infrastructural, and labor constraints. This is significant since all stored seeds will eventually succumb during storage due to accumulated aging damage that cannot be resolved upon rehydration. Moreover, the level and rate of viability loss due to aging within a seed lot increases with increasing seed water content, RH, and storage temperature (Ellis and Roberts, 1981; Walters, 1998, 2015; Walters et al., 2010). Therefore, seeds will tend to have limited shelf life when stored without prior moisture content adjustments, in environments of fluctuating or persistently high $\mathrm{RH}$ and heat, or under conditions where only one or two important storage components (e.g., seed water content, $\mathrm{RH}$, temperature) are controlled. Consequently, an important first step for seed managers is to understand the response of seeds to dehydration before storage (Food and Agriculture Organization of the United Nations, 2014). This is particularly true for nondomesticated wildflower species of horticultural importance, where a priori knowledge of storage behavior is almost always lacking (Kauth and Pérez, 2011; Milstein, 2005; Walters, 2015).

Similarly, seed vigor is a concept that attempts to reconcile the biochemical, physiological, and genetic properties of seed lots contributing to germination and establishment potential. Seed lots displaying high vigor are characterized by rapid and uniform germination to high percentages despite exposure to unfavorable storage or establishment conditions (Powell, 2006). It should be noted, however, that the sensitivity or tolerance to stress can be uncoupled from germination rate or uniformity. In other words, sensitivity to stress as displayed by a loss of germination ability (i.e., reduced germination percentage) can precede reductions in germination rate or uniformity. Nevertheless, seed aging is a main source of vigor loss. In fact, the relationship between seed deterioration and vigor is inverse (Powell, 2006; Seed Vigor Testing Committee, 2002).

In the present study, we examined the desiccation tolerance of mature, freshly harvested Gaillardia pulchella seeds to gain some perspective on the storage potential of this species. Additionally, we examined responses to aging stress in an attempt to understand vigor of fresh seeds. We selected G. pulchella because it is in high demand and producers seek more information related to the seed physiology of wildflowers (Kauth and Pérez, 2011). We ask: 1) how are seed-water relations characterized; 2) what is the relationship of seed-water relations to desiccation tolerance; 3) does germination response change following moderate to severe desiccation stress; and 4) how does aging stress influence seed vigor. We used water sorption isotherms, equilibrium RH drying techniques, and SSAA assays to address these questions.

\section{Materials and Methods}

Seed materials and initial measurements. Gaillardia pulchella (Asteraceae) is an herbaceous forb native to the United States and naturally occurs within coastal areas throughout Florida. The showy capitula of this shortlived perennial bloom year-round in the southern peninsula and from late spring to early fall in northern Florida. Gaillardia pulchella produces achenes referred to hereafter as seeds. We received a lot of mature seeds from a wildflower seed producer located in southwestern Florida. The producer harvested seeds on 15 May 2014 and shipped these to the Seed Biology Laboratory (University of Florida, Gainesville, FL) via standard mail. We placed the seeds in a large paper bag on the laboratory benchtop upon receipt. We refer to this as the 2014 lot. Seeds of the 2014 lot were exposed to ambient laboratory conditions $\left(\approx 24{ }^{\circ} \mathrm{C} ; 35 \% \mathrm{RH}\right)$ for $3 \mathrm{~d}$ before the start of experimentation.

We randomly selected 100 seeds from the 2014 lot and divided this sample into four subsamples of 25 seeds each. We then measured the fresh and dry mass of each sample 
gravimetrically. We obtained dry mass after heating seeds at $105^{\circ} \mathrm{C}$ for $96 \mathrm{~h}$ in a forced air oven. We calculated initial seed water content from fresh and dry mass and present this as grams $\mathrm{H}_{2} \mathrm{O}$ per gram dry mass $\left(\mathrm{g} \cdot \mathrm{g}^{-1}\right)$.

Water sorption isotherms and desiccation stress assay. We determined relationships between seed water content and $\mathrm{RH}$ by constructing water sorption isotherms. We randomly selected 2400 seeds from the 2014 seed lot and divided this working lot into 96 subsamples of 25 seeds each. We arranged subsamples in a single layer within separate $20-\times 90-\mathrm{mm}$ petri dishes and randomly assigned subsamples to 12 saturated salt solutions (Table 1). We prepared saturated solutions by placing $100 \mathrm{~g}$ of reagent grade salts into $150-\mathrm{mm}$ petri dishes. With the exception of $\mathrm{P}_{2} \mathrm{O}_{5}$, we slowly mixed distilled, deionized water into the salts until a slush or slurry, depending on the salt, was achieved. However, we added just enough water to allow fusion of $\mathrm{KOH}$ pellets.

Seeds were equilibrated at $25{ }^{\circ} \mathrm{C}$ over the various saturated salt solutions within sealed glass desiccators ( $250 \mathrm{~mm}$ i.d.) until constant fresh weight was achieved. Fresh weight was monitored gravimetrically with one subsample. Seeds equilibrated in $\approx 3$ to $10 \mathrm{~d}$ depending on the salt solution. We removed four subsamples upon equilibration to determine seed water content. Additionally, we used the remaining four subsamples to assay desiccation tolerance by evaluating germination ability following equilibration to low water potentials.

Seed vigor analysis. We used the SSAA test (Jianhua and McDonald, 1996) to analyze seed vigor of the 2014 lot. We randomly selected 180 seeds from the lot and then subdivided this sample into three subsamples of 60 seeds. We arranged the subsamples as a single layer on top of 18 mesh $(1.0-\mathrm{mm})$ wire trays (AAT; Hoffman Manufacturing, Inc., Jefferson, OR). We then made a saturated salt

Table 1. Relative humidity $(\mathrm{RH})$ and water potential of the air above various saturated salt solutions within a closed desiccation chamber at $25^{\circ} \mathrm{C}$. $\mathrm{RH}$ values are from Vertucci and Ross (1993 and referenced therein). RH was converted to water potential using the formula: $\mathrm{MPa}=\frac{R . T}{V} \ln \frac{R H}{100}$, where $R=$ universal gas constant $(8.314 \times$ $\left.10^{-3} \mathrm{~kJ} \cdot \mathrm{mol}^{-1} \cdot \mathrm{K}^{-1}\right), T=$ absolute temperature in $\mathrm{K}, \bar{V}_{\mathrm{w}}$ is the partial molal volume of water $(18 \times$ $10^{-6} \mathrm{~m}^{3} \cdot \mathrm{mol}^{-1}$ ), and $R H=$ percentage of $\mathrm{RH}$ (Sun, 2002; Vertucci and Roos, 1993).

\begin{tabular}{lcc}
\hline Salt & $\begin{array}{r}\mathrm{RH}(\%) \\
\text { at } 25^{\circ} \mathrm{C}\end{array}$ & $\begin{array}{c}\text { Water potential } \\
(-\mathrm{MPa})\end{array}$ \\
\hline $\mathrm{KNO}_{3}$ & 91.0 & 12.9 \\
$\mathrm{KCl}$ & 85.0 & 22.3 \\
$\mathrm{NaCl}$ & 75.0 & 39.5 \\
$\mathrm{Ca}\left(\mathrm{NO}_{3}\right)_{2}$ & 50.5 & 93.8 \\
$\mathrm{NaI}$ & 38.0 & 132.8 \\
$\mathrm{MgCl}_{2}$ & 32.5 & 154.3 \\
$\mathrm{CaCl}$ & 29.5 & 167.6 \\
$\mathrm{KAc}$ & 25.0 & 190.3 \\
$\mathrm{LiCl}$ & 13.0 & 280.1 \\
$\mathrm{KOH}$ & 8.0 & 346.7 \\
$\mathrm{ZnCl}_{2}$ & 5.5 & 398.2 \\
$\mathrm{P}_{2} \mathrm{O}_{5}$ & 0.5 & 797.5 \\
\hline
\end{tabular}

solution by heating $100 \mathrm{~mL}$ of $\mathrm{H}_{2} \mathrm{O}$ to $41{ }^{\circ} \mathrm{C}$ followed by the addition of $40 \mathrm{~g}$ of reagent grade $\mathrm{NaCl}$. We mixed the solution until it had the appearance of an icy slush and poured the mixture into the bottom of an acrylic-accelerated aging container $(156 \mathrm{C}$, Hoffman Manufacturing, Inc.). We immediately assigned one of the trays at random to the container and transferred the container to an incubator (I-30-VL; Percival Scientific, Inc., Perry, IA) set at $41{ }^{\circ} \mathrm{C}$ with a 12 -h alternating photoperiod $(57 \pm$ $\left.7 \mu \mathrm{mol} \cdot \mathrm{m}^{-2} \cdot \mathrm{s}^{-1}\right)$. We repeated this process until all containers were loaded into the chamber. We exposed the seeds to the SSAA conditions for 24,48 , or $72 \mathrm{~h}$. We quickly removed 10 seeds from a selected container for water content determinations after each time point. We determined water content as described above. However, in this case, we used five subsamples of two seeds each. We then divided the remaining 50 seeds from each container into 5 subsamples of 10 seeds each for germination testing.

Germination assay. We rehydrated seeds for $45 \mathrm{~min}$ on damp blotter upon removal

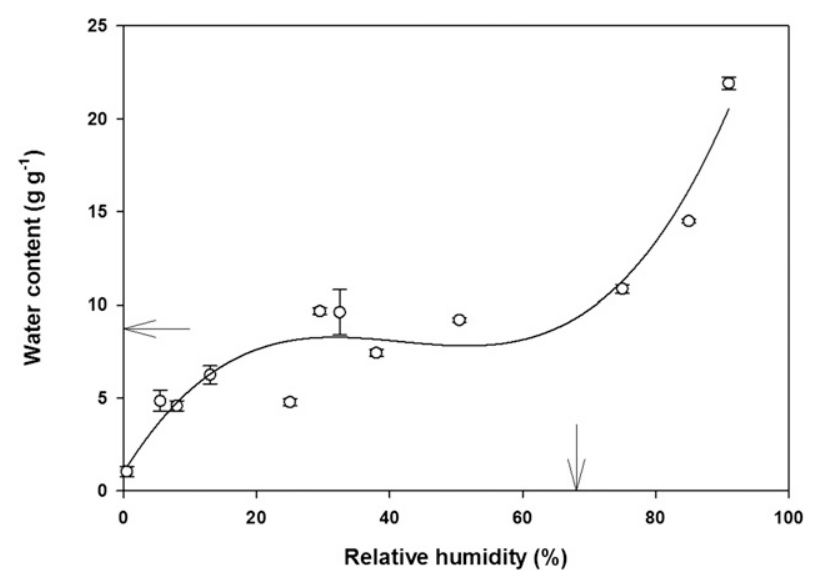

Fig. 1. Relationships between initial seed water content and relative humidity (RH) of Gaillardia pulchella seeds harvested in 2014. Arrows denote initial water content ( $y$-axis) and estimated RH ( $x$-axis).

Table 2. Germination parameters for Gaillardia pulchella seeds exposed to desiccation stress via equilibration to various relative humidity (RH) conditions. Seeds were tested in 2014 within a few days of harvest.

\begin{tabular}{cccccc}
\hline RH $(\%)$ & $n$ & $\begin{array}{c}\text { Final } \\
\text { germination }(\%)\end{array}$ & $\begin{array}{c}\text { Lag }^{\mathrm{z}}(\mathrm{d}) \\
(95 \% \mathrm{CI})\end{array}$ & $\begin{array}{c}\text { Median germination } \\
\text { time }\left(t_{50}\right) \text { in } \mathrm{d}^{\mathrm{y}}(95 \% \mathrm{CI})\end{array}$ & $\begin{array}{c}\text { Germination } \\
\text { rate }^{\mathrm{x}}\end{array}$ \\
\hline 0.5 & 100 & 74 & $2.0(2.0-2.0)$ & $6(3-6)$ & 0.17 \\
5.5 & 100 & 76 & $2.0(1.0-3.0)$ & $6(-,-\mathrm{w})$ & 0.17 \\
8.0 & 100 & 75 & $2.0(2.0-2.0)$ & $4(4-5)$ & 0.25 \\
13.0 & 100 & 71 & $2.0(2.0-2.0)$ & $4(3-5)$ & 0.25 \\
25.0 & 100 & 70 & $1.3(0.8-1.7)$ & $7(4-7)$ & 0.14 \\
32.5 & 100 & 81 & $3.0(3.0-3.0)$ & $4(4-5)$ & 0.25 \\
38.0 & 100 & 70 & $2.3(1.8-2.7)$ & $4(4-5)$ & 0.25 \\
50.5 & 100 & 80 & $2.0(2.0-2.0)$ & $4(3-4)$ & 0.25 \\
75.0 & 100 & 78 & $1.0(1.0-1.0)$ & $5(-,-)$ & 0.20 \\
85.0 & 100 & 80 & $1.0(1.0-1.0)$ & $4(-,-)$ & 0.25 \\
91.0 & 100 & 76 & $3.0(3.0-3.0)$ & $4(-,-)$ & 0.25 \\
\hline
\end{tabular}

${ }^{2} \mathrm{Lag}$ time denotes time in days from sowing for seeds to meet the prescribed definition of germination. y Estimates of median germination time correspond to the smallest event times given that the probability of not germinating is $>0.50$ and are derived from Kaplan-Meier product limit survival estimates. Therefore, $t_{50}$ values provide estimates of the time for seeds to reach the 50th (median) percentile of germination. ${ }^{\times}$Germination rate was calculated as $1 \times t_{50}{ }^{-1}$.

wThe curve representing the upper or lower confidence limit lies above the median value resulting in an inestimable confidence limit value.

$\mathrm{CI}=$ confidence interval. 

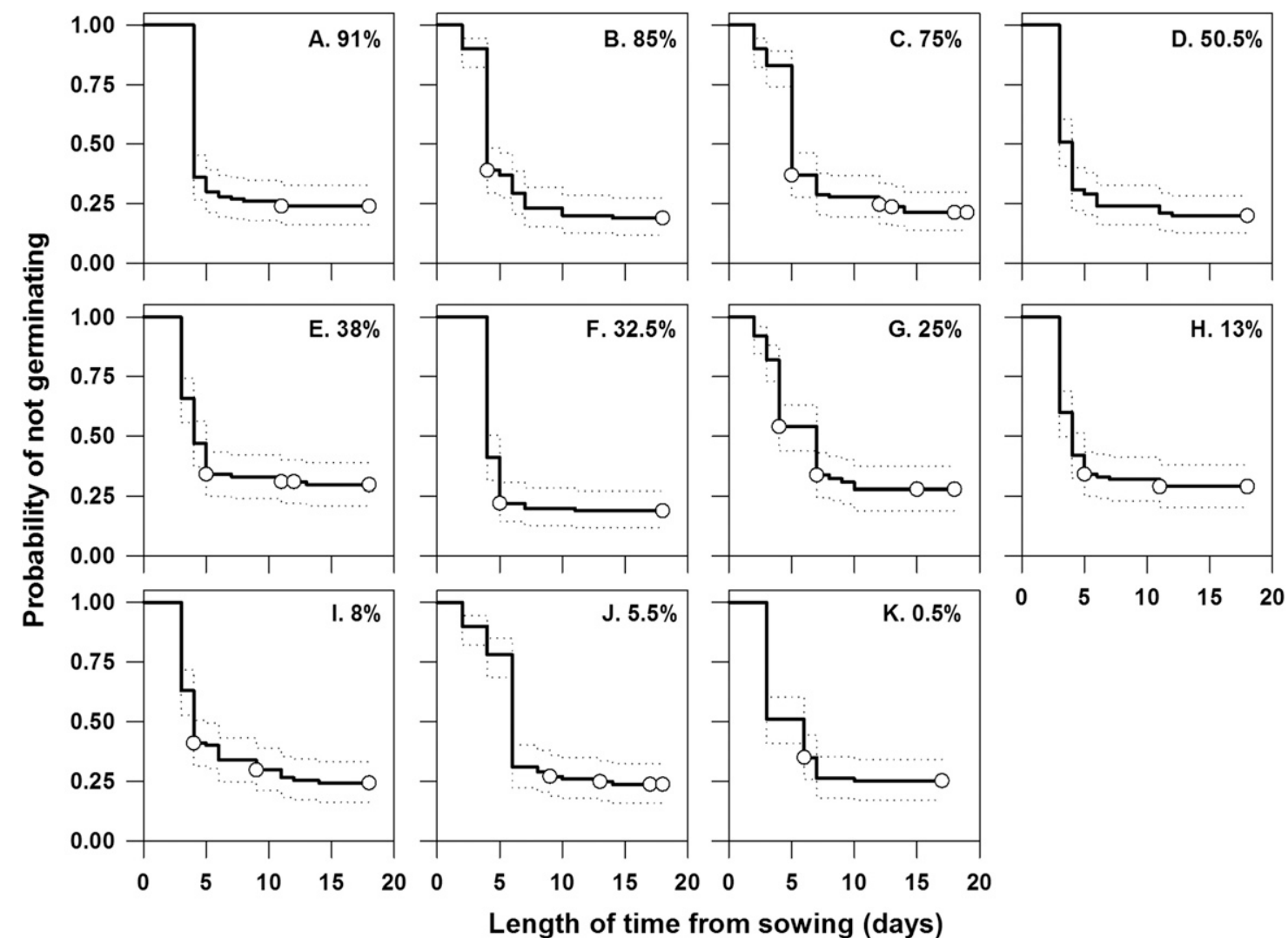

Fig. 2. Kaplan-Meier estimates of survivor functions for Gaillardia pulchella seeds harvested in 2014 and equilibrated to various relative humidity levels. Dotted lines represent pointwise $95 \%$ confidence intervals. Open circles represent censored observations.

Table 3. Germination parameters for Gaillardia pulchella seeds following exposure to saturated salt accelerated aging (SSAA) conditions for 24, 48, or $72 \mathrm{~h}$. Seeds were harvested in 2014 and tested within a few days of harvest.

\begin{tabular}{lccccc}
\hline & & \multicolumn{3}{c}{$\begin{array}{c}\text { Median germination } \\
\text { time }\left(t_{50}\right) \text { in } \mathrm{d}^{\mathbf{z}}\end{array}$} \\
SSAA duration $(\mathrm{h})$ & $n$ & Final germination $(\%)$ & $\begin{array}{c}\text { Lag }(\mathrm{d}) \\
(95 \% \mathrm{CI})\end{array}$ & $\begin{array}{c}(95 \% \mathrm{CI}) \\
\text { Germination rate }\end{array}$ \\
\hline 24 & 50 & 74 & $1.8(1.4-2.2)$ & $6.0(3-7)$ & 0.17 \\
48 & 50 & 76 & $1.0(1.0-1.0)$ & $5.0(5-6)$ & 0.20 \\
72 & 50 & 64 & $3.0(3.0-3.0)$ & $7.5(4-14)$ & 0.13 \\
\hline
\end{tabular}

${ }^{\mathrm{z}}$ Estimates of median germination time correspond to the smallest event times given that the probability of not germinating is $>0.50$ and are derived from Kaplan-Meier product limit survival estimates. Therefore, $t_{50}$ values provide estimates of the time for seeds to reach the 50th (median) percentile of germination. $\mathrm{CI}=$ confidence interval.

emergence events such as emergence of cotyledons that a more conservative approach to measure the completion of germination has been applied. We removed germinated seeds from dishes after each observation.

Data analysis. We estimated the water content-water potential isotherm via best-fit nonlinear regression (Vertucci and Leopold, 1984). Furthermore, we used non- and semiparametric time-to-event analyses to evaluate temporal patterns of germination and construct Cox regression models. Theoretical and applied aspects of time-to-event analysis have been presented elsewhere. Briefly, timeto-event analyses offer several advantages over traditional techniques, such as analysis of variance and curve fitting, including but not limited to: 1) accommodation of censored observations, non-normal data, and heterogeneous variances; 2) analyses based on the distribution of event times for individual experimental units rather than cumulative results; 3) evaluation of multiple quantitative and qualitative covariates; 4) the ability to incorporate time-dependent covariates; and 5) simultaneous assessment of multiple, independent transitional events that may occur to experimental units (Allison, 2010; Cox, 1972; Dubois et al., 2003; Genna et al., 2015; Hay et al., 2014; Kleinbaum and Klein, 2005; McNair et al., 2012; Pérez and Kettner, 2013; Scott et al., 1984).

We performed all time-to-event analyses in SAS (v 9.4; SAS Institute, Inc., Cary, NC). Germination was the event of interest. Therefore, we coded seeds that had germinated during the experimental period as 1 . Seeds that did not germinate by the termination of an experiment were right-censored and coded as 0 . We generated Kaplan-Meier estimates of survivor functions for seeds exposed to desiccation or SSAA treatments and stratified survivor functions by RH or SSAA duration. We tested the null hypothesis that survivor functions were the same within treatments by calculating the log-rank statistic. We calculated germination rate as the inverse of median germination time $\left(1 \times t_{0.50}{ }^{-1}\right)$. We used the so-called exact method to account for large proportions of tied survival times when constructing Cox regression models (Allison, 2010).

\section{Results and Discussion}

Water sorption isotherm. The moisture sorption isotherm generated for G. pulchella seeds displayed a reverse sigmoidal shape. Initial seed moisture content was $8.7 \pm$ $0.4 \mathrm{~g} \cdot \mathrm{g}^{-1}$ (mean $\pm \mathrm{SD}$ ), which corresponds to $\approx 68 \%$ RH (Fig. 1). Seed RH was converted to water potential as described in Table 1 . This calculation yielded an initial seed water potential of $\approx-53 \mathrm{MPa}$.

Seed-water relations characterized by reverse sigmoidal isotherms have been reported for desiccation-tolerant seeds, and the calculated water potential suggests that seeds of $G$. pulchella undergo considerable maturation drying in planta (Pérez et al., 2012; Vertucci and Leopold, 1984; Vertucci and Roos, 1990; Walters et al., 2002). Maturation drying is one of the key stages of seed development differentiating seeds capable of tolerating substantial postharvest desiccation from desiccation-sensitive seeds that may experience comparatively reduced 

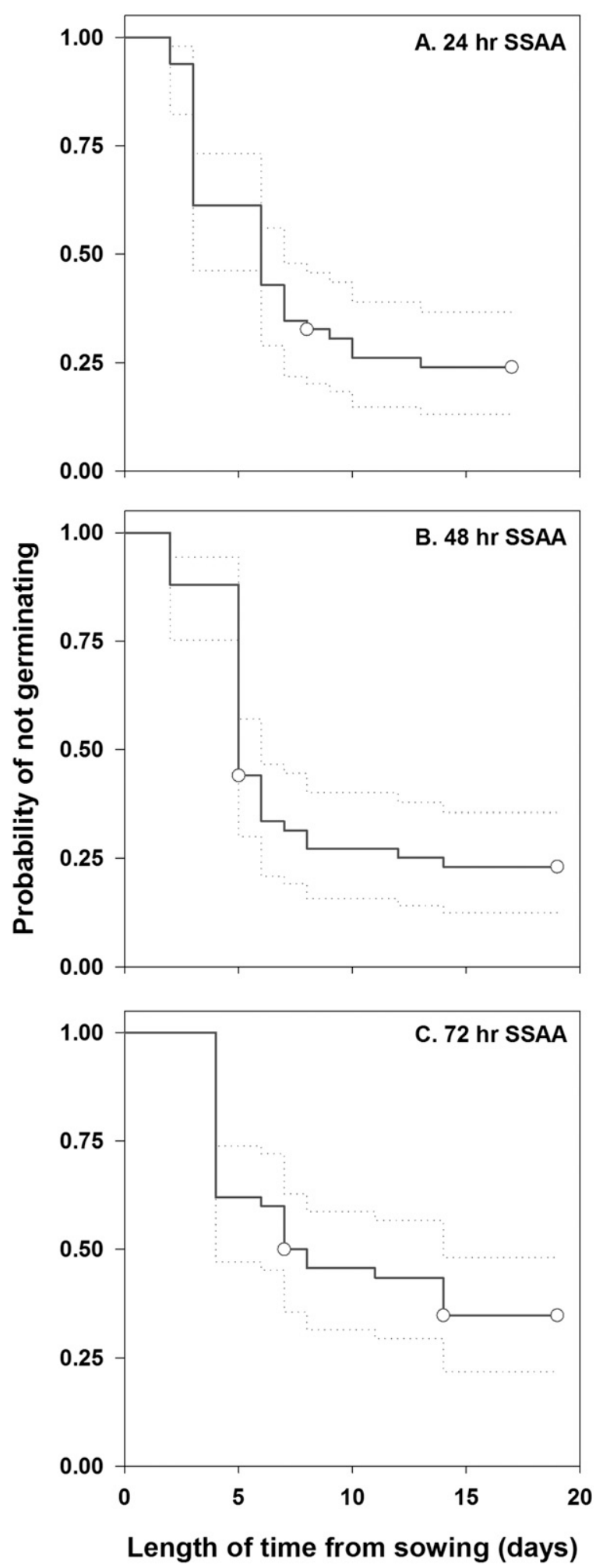

Fig. 3. Kaplan-Meier estimates of survivor functions for Gaillardia pulchella seeds harvested in 2014 and exposed to 24,48 , or $72 \mathrm{~h}$ of saturated salt accelerated aging treatments. Dotted lines represent pointwise $95 \%$ confidence intervals. Open circles represent censored observations.

levels of drying in planta (Kermode and Finch-Savage, 2002; Walters et al., 2002). Furthermore, the initial seed water potential reported here for $G$. pulchella was well below lethal water potential limits of $\approx-10$ to $-15 \mathrm{MPa}$ identified for species possessing desiccation-sensitive seeds (Berjak and Pammenter, 2008; Walters et al., 2002).
Seed response to desiccation stress. Final germination for $G$. pulchella seeds remained consistently high (range $70 \%$ to $81 \%$ ) regardless of equilibration to low RH (Table 2). Seeds also displayed similar temporal patterns of germination across all drying treatments (Fig. 2). For example, seeds commenced germination within $3 \mathrm{~d}$ of sowing and median time for germination (i.e., $t_{50}$ ) ranged between 4 and $7 \mathrm{~d}$. Seeds tended to germinate more rapidly between $32.5 \%$ and $91 \% \mathrm{RH}$ than to greater levels (i.e., $25 \%$ to $0.5 \% \mathrm{RH}$ ) of drying stress (Fig. 2; Table 2); however, these differences were not significant. The null hypothesis that temporal patterns of germination (i.e., survivor functions) were the same across all RH treatments was not rejected (log-rank $\left.\chi_{10}^{2}=15.77 ; P=0.11\right)$. Likewise, Cox regression revealed no significant effect (Wald $\chi^{2}{ }_{1}=0.55 ; P=0.46$; hazard ratio $\left.=1.00\right)$ of $\mathrm{RH}$ on germination.

Desiccation tolerance in G. pulchella seeds was confirmed via equilibration drying treatments. For instance, seed water potential was reduced to levels considerably lower (i.e., -93.8 to $-797.5 \mathrm{MPa}$ ) than the initial value of $-53 \mathrm{MPa}$. These levels of desiccation stress are thought to induce physiological and physical changes within cells, such as membrane damage, production of reactive oxygen species, loss of protein flexibility, and cellular matrix collapse, that are lethal if irreversible upon subsequent rehydration (Walters and Koster, 2007; Walters et al., 2010;). Gaillardia pulchella seeds appear to possess mechanisms for tolerating and recovering from such stresses as shown by similar survivor functions (Fig. 2; Table 2) and nonsignificant Cox regression parameters across drying treatments. Walters and Koster (2007) and Pérez et al. (2012) argue that $>35 \%$ of cellular volume must be composed of dry matter to buffer against mechanical strain associated with severe desiccation. We speculate that seeds of $G$. pulchella accumulate maximum dry matter reserves (i.e., physiological maturity) during the developmental program, thus rendering seeds tolerant of high levels of postharvest desiccation. Future seed developmental studies could confirm the levels of dry matter accumulation in G. pulchella.

Furthermore, tolerance to high levels of desiccation stress is reasonable given that G. pulchella occurs naturally within coastal dune ecosystems and other habitats characterized by well-drained sands and exposure to full sun throughout the day. Seeds in these habitats are frequently exposed to high temperatures and very low soil water potentials that may facilitate repeated drying events. Maintenance of germination ability following exposure to extreme drying also suggests that seeds of $G$. pulchella are tolerant of the drying necessary for storage under genebank conditions and supports the assumption that seeds of this taxa probably possess orthodox storage physiology (Royal Botanic Gardens Kew, 2015). However, seed developmental studies, assays investigating survival and aging following combinations of drying and low temperature, and analyses of triacylglycerol crystallization are needed to pinpoint $G$. pulchella seed storage physiology (Kermode and FinchSavage, 2002; Pérez et al., 2012; Walters, 2015; Walters and Koster, 2007; Walters et al., 2010).

HortScience Vol. 51(2) February 2016 
Seed germination following accelerated aging stress. Seeds of $G$. pulchella exposed to 24 or $48 \mathrm{~h}$ of aging stress reach final germination percentages similar to seeds exposed to desiccation stress. However, germination decreased after $72 \mathrm{~h}$ of SSAA. For instance, final germination of seeds treated with $72 \mathrm{~h}$ of SSAA decreased by $\approx 17 \%$ compared with 24 or 48 h of SSAA (Tables 2 and 3). The probability of not germinating declined almost continually for seeds harvested in 2014 following exposure to 24,48 , or $72 \mathrm{~h}$ of SSAA despite the decrease in final germination percent (Fig. 3; Table 3). Seeds commenced germinating before day 2 following 24 or 48 h of SSAA, but lag time was extended until day 3 following $72 \mathrm{~h}$ of SSAA. Similarly, germination rate (i.e., $1 \times t_{50}{ }^{-1}$ ) was slower for seeds exposed to $72 \mathrm{~h}$ of SSAA (Fig. 3; Table 3). The null hypothesis that survivor functions were the same across SSAA durations was not rejected $\left(\log\right.$-rank $\chi^{2}{ }_{2}=2.73$; $P=0.26)$ lot. Similarly, Cox regression did not detect a significant influence of SSAA duration on germination (Wald $\chi^{2}{ }_{1}=1.95$; $P=0.16$; hazard ratio $=0.99)$ lot.

Results of the vigor assay suggest that fresh G. pulchella seeds exhibit a high degree of vigor. Therefore, fresh seeds should be tolerant of variable and stressful field or greenhouse conditions. Growers would face increased costs associated with propagation and production if low vigor seed lots are used. Collectively, this highlights the importance of: 1) handling seeds in a manner that will maximize storage shelf life and 2) focusing on initial seed lot quality.

Likewise, global climate change is predicted to increase ambient temperatures, the incidence of drought and seasonal fluctuations in these parameters thereby possibly complicating the seedling establishment environment (International Panel on Climate Change, 2007; Walck et al., 2011). It is conceivable that low vigor seeds of $G$. pulchella may not develop into seedlings under forecasted climate scenarios or when seasonal conditions become extreme. Von Holle et al. (2010) have shown that areas outside of artic and temperate zones, such as Florida, have experienced increased variability in surface temperatures due to climate change and that these changes are influencing plant responses. Likewise, Kettner and Pérez (2012) and Pérez and Kettner (2013) found that relatively small increases in ambient temperatures considerably reduce the germination response and viability status of Florida native wildflowers.

\section{Conclusion}

Germplasm storage represents an important tool for conserving plant genetic diversity and enhancing commercial production of horticulturally desirable taxa. Fresh G. pulchella seeds exhibit tolerance to extreme levels of desiccation. Therefore, maintenance of seed viability under genebank storage conditions is feasible for this species. However, to maintain and extend seed shelf life of desiccationtolerant seeds, it is imperative to couple postharvest drying to low water contents with cold storage. Moreover, current and future use of high vigor $G$. pulchella seeds is essential to establish this wildflower for applications, including large-scale wildflower plantings, highway right-of-ways beautification activities, land rehabilitation projects, and development of seed production plots.

\section{Literature Cited}

Allison, P.D. 2010. Survival analysis using SAS $^{\circledR}$ : A practical guide. SAS Institute Inc., Cary, NC.

Berjak, P. and N. Pammenter. 2008. From Avicennia to Zizania: Seed recalcitrance in perspective. Ann. Bot. 101:213-228.

Cox, D.R. 1972. Regression models and life-tables. J. Roy. Stat. Soc. B. 34:187-220.

Dubois, J.-J., J. Osborne, and F. Blazich. 2003. Statistical analysis of time-to-event data: Applications in horticultural science. HortScience 38:693.

Ellis, R.H. and E.H. Roberts. 1981. The quantification of aging and survival in orthodox seeds. Seed Sci. Technol. 9:373-409.

Food and Agriculture Organization of the United Nations. 2014. Genebank standards for plant genetic resources for food and agriculture, $\mathrm{p}$. 182. Food and Agriculture Organization of the United Nations, Rome, Italy.

Genna, N.G., M.E. Kane, and H.E. Pérez. 2015. Simultaneous assessment of germination and infection dose-repsonses in fungicide-treated seeds with non- and semi-parametric statistical methods. Seed Sci. Technol. 43:168-186.

Hay, F.R., A. Mead, and M. Bloomberg. 2014. Modelling seed germination in response to continuous variables: Use and limitations of probit analysis and alternative approaches. Seed Sci. Res. 24:165-186.

International Panel on Climate Change. 2007. Climate change 2007: The physical science basis, p. 847-940. In: S. Solomon, D. Qin, M. Manning, Z. Chen, M. Marquis, K.B. Averyt, M. Tignor, and H.L. Miller (eds.). Contribution of Working Group I to the Fourth Assessment Report of the Intergovernmental Panel on Climate Change, 2007. Cambridge University Press, Cambridge, UK.

Jianhua, Z. and M.B. McDonald. 1996. The saturated salt accelerated aging test for small-seeded crops. Seed Sci. Technol. 25:123-131.

Kauth, P.J. and H.E. Pérez. 2011. Industry survey of the native wildflower market in Florida. HortTechnology 21:779-788.

Kermode, A.R. and W.E. Finch-Savage. 2002. Desiccation sensitivity in orthodox and recalcitrant seeds in relation to development, p. 149-184. In: M. Black and H.W. Pritchard (eds.). Desiccation and survival in plants: Drying without dying. CABI Publishing, Wallingford, UK.

Kettner, K. and H.E. Pérez. 2012. Dose-response of germinating Rudbeckia mollis (Asteraceae) seeds exposed to various thermal scenarios. Seed Sci. Res. 22:191-197.

Kleinbaum, D.G. and M. Klein. 2005. Survival analysis a self-learning text. Springer, New York.

McNair, J.N., A. Sunkara, and D. Frobish. 2012. How to analyse seed germination data using statistical time-to-event analysis: Non-parametric and semiparametric methods. Seed Sci. Res. 22:77-95.

Milstein, G.P. 2005. The uses and potential of wildflower seed in landscaping, p. 39-51. In: M.B. McDonald and F.Y. Kwong (eds.). Flower seeds biology and technology. CABI Publishing, Wallingford, UK

Pérez, H.E., L.M. Hill, and C. Walters. 2012. An analysis of embryo development in palm: Interactions between dry matter accumulation and water relations in Pritchardia remota (Arecaceae). Seed Sci. Res. 22:97-111.

Pérez, H.E. and K. Kettner. 2013. Characterizing Ipomopsis rubra (Polemoniaceae) germination under various thermal scenarios with nonparametric and semi-parametric statistical methods. Planta 238:771-784.

Powell, A.A. 2006. Vigour testing, p. 741-743. In: M. Black, J.D. Bewley, and P. Halmer (eds.). The encyclopedia of seeds: Science, technology and uses. CABI Publishing, Wallingford, UK.

Roberts, E.H. 1973. Predicting the storage life of seeds. Seed Sci. Technol. 1:499-514.

Royal Botanic Gardens Kew. 2015. Seed Information Database (SID) Version 7.1. Kew. 1 May 2015. <http://data.kew.org/sid/>.

Scott, S.J., R.A. Jones, and W.A. Williams. 1984. Review of data analysis methods for seed germination. Crop Sci. 24:1192-1199.

Seed Vigor Testing Committee. 2002. Seed vigor testing handbook. Association of Official Seed Analysts, Ithaca, NY

Sun, W.Q. 2002. Methods for the study of water relations under desiccation stress, p. 47-91. In: M. Black and H.W. Pritchard (eds.). Desiccation and survival in plants: Drying without dying. CABI Publishing, Wallingford, UK.

Vertucci, C.W. and A.C. Leopold. 1984. Bound water in soybean seed and its relation to respiration and imbibitional damage. Plant Physiol. 75:114-117.

Vertucci, C.W. and E.E. Roos. 1990. Theoretical basis of protocols for seed storage. Plant Physiol. 94:1019-1023.

Vertucci, C.W. and E.E. Roos. 1993. Theoretical basis of protocols for seed storage II. The influence of temperature on optimal moisture levels. Seed Sci. Res. 3:201-213.

Von Holle, B., Y. Wei, and D. Nickerson. 2010. Climatic variability leads to later seasonal flowering of Floridian plants. PLoS One 5:e11500, doi: 10.1371/journal.pone.0011500.

Walck, J.L., S.N. Hidayati, K.W. Dixon, K. Thompson, and P. Poschold. 2011. Climate change and plant regeneration from seed. Glob. Change Biol. 17:2145-2161.

Walters, C. 1998. Understanding the mechanisms and kintectics of seed aging. Seed Sci. Res. 8:223-244.

Walters, C. 2015. Genebanking seeds from natural populations. Nat. Areas J. 35:98-105.

Walters, C., D. Ballesteros, and V.A. Vertucci. 2010 Structural mechanics of seed deterioration: Standing the test of time. Plant Sci. 179:565-573.

Walters, C., J. Farrant, N. Pammenter, and P. Berjak. 2002. Desiccation stress and damage, p. 263-292. In: M. Black and H.W. Pritchard (eds.). Desiccation and survival in plants: Drying without dying. CABI Publishing, Wallingford, UK.

Walters, C. and K. Koster. 2007. Structural dynamics and desiccation damage in plant reproductive organs, p. 251-279. In: M.A. Jenks and A.J. Wood (eds.). Plant desiccation tolerance. Blackwell Publishing, Ames, IA. 